\title{
A Decade of Legally Practicing the Environmental Assessment Tool
}

\author{
Batu Krishna Uprety
}

Abstract. Two and half-decades of experience in implementing environmental assessment (EA) tools through policies and legislations have contributed to integrating environmental aspects into development projects in Nepal. The Enforcement of Environment Protection Act (EPA) of 1996 and the Environment Protection Rules (EPR) of 1997 have expanded the application of EA tools for the prescribed proposals. After the enforcement of EPA and EPR, the government has approved the EIA reports of 72 projects. In 2006 alone, EIA reports of 22 projects were approved. In general, however, approval of EIA reports has no meaning unless they are effectively implemented. The benefits of EA could be realised after environmental monitoring and auditing that helps to know the level of compliance and effectiveness of mitigation measures. This article outlines the causes of delay decision and major initiatives taken to make the EA more effective, realistic and practical.

Nepal is implementing policies, laws and guidelines for project-level environmental assessment (Initial Environmental Examination, or IEE, and Environmental Impact Assessment, or EIA) with a view to make development projects environment-friendly. The conducting of EIA begon in the 1980 s along with the policy of the Sixth Plan (1980-85). From Six Plan to Eighth Plan, the policies focussed on carrying out EIA of major development projects. EIA reports for some development projects were prepared during this period. The government implemented the National EIA Guidelines of 1993, and separate EIA guidelines for the forestry and industry sectors since 1995, to assist the proponents in preparing the EA reports. The Ninth Plan (1997-2002) emphasised participatory EIA, while the current Tenth Plan (2002-07) has also realised the need for carrying out environmental monitoring and Strategic Environmental Assessment (SEA). Sectoral policies and strategies also emphasise the importance of EIA. They include: (1) the Nepal Environmental Policy and Action Plan of 1993, (2) the Tourism Policy of 1995, (3) the National Solid Waste Management Policy of 1996, (4) the Public Infrastructure (Build, Operate and Transfer) Policy of 2000, (5) the Hydropower Development Policy of 2001, (6) the National Wetlands Policy of 2003, (7) the Irrigation Policy of 2003, (8) the Sustainable Development Agenda for Nepal of 2003, (9) the Water Resources Strategy of 2002, and (10) the Nepal Biodiversity Strategy of 2002. Most of the policies formulated after 1990 and Rio Earth Summit of 1992 have urged using EA tools.

Realizing the benefits EIA in making projects environment-friendly and sustainable, the IEE and EIA were made mandatory to prescribed projects after the enforcement of the Environment Protection Act (EPA) of 1996 and the Environment Protection Regulations (EPR) of 1997, in June 1997. The Act and Rules have provisions for approval processes of IEE and EIA reports, and for conducting environmental monitoring and auditing. Based on the legal provisions, the concerned ministry (i.e., the ministry related to the proposal) is empowered to approve the IEE report. In case of EIA reports, the Ministry of Environment, Science and Technology (MOEST) is legally empowered to approve the EIA and its associated reports (scoping document and TOR), and to conduct environmental auditing. However, the concerned ministry is legally responsible to conduct the environmental monitoring. Details of the approval processes are included in the EPA and EPR.

The quality of EIA reports has improved over the years, but there still are problems of copying and pasting. There are ample opportunities to make the EIA report practical, realistic and implementable. The urgent need is to maintain professional ethics while preparing the EIA report. The linkage amongst the baseline data and information with impacts and corresponding environment protection measures, monitoring and auditing parameters/indicators also improves the report quality. Environmental monitoring and auditing also contributes towards making EIA reports practical, by knowing the level of environmental compliance and the effectiveness of the environment protection measures. This will, in turn, help in refining assessment tools and in selecting practical, realistic, and implementable measures.

\section{Approved EIA reports}

After enforcement of the environmental laws, up to the end of October 2007 the MOEST has approved EIA reports for 72 projects. In the year 2006 alone, 22 such EIA reports were approved. This means that the projects were given environmental clearance for construction and/or implementation. Most of the EIA 
reports were prepared for water resources (hydropower generation, transmission line and irrigation projects), forestry (mostly pine resin collection), roads and drinking water projects. Some EIA reports for hospitals, sanitary landfill sites and waste management projects have also been approved.

See Tables 1 and 2.

Approved EIA Reports (Sector-wise)

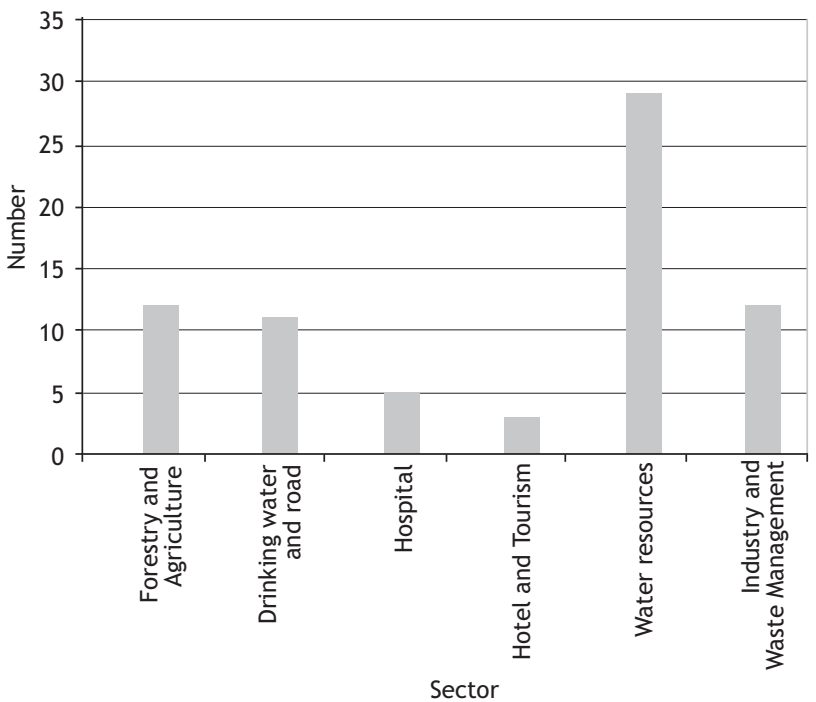

Approved EIA Reports (Year-wise)

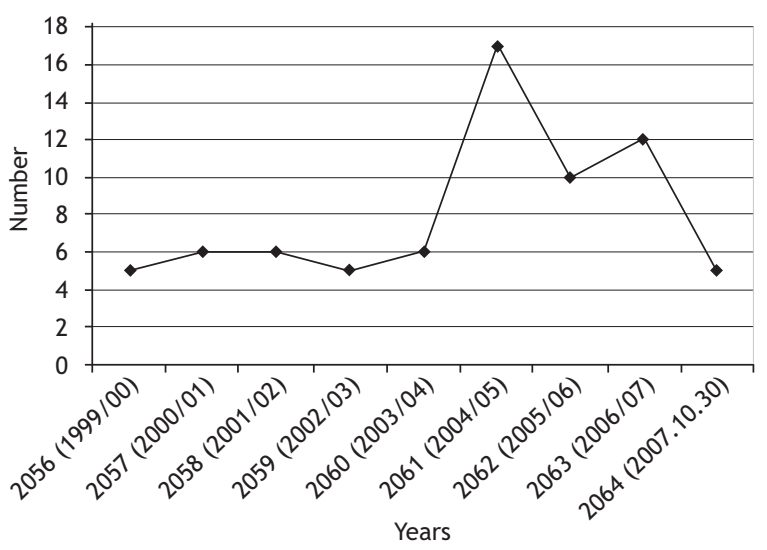

About eight EIA reports are under refinement, as of October 2007. The EIA report of four projects (hydropower generation, irrigation and transmission line projects) planned for implementation in the national park areas are pending for approval due to attraction of the National Parks and Wildlife Conservation Act of 1973.

\section{Reasons for delay approval}

The MOEST is often 'blamed' by different interest groups as the institution that takes the most time to approve EIAs and associated reports. In most cases, EIAs and associated reports are prepared by the consultants on behalf of the proponent; in some cases the proponents do not know what is included in them. However, as the environmental law does not recognise consultants, the question arises: who owns the report, the consultant or the proponent. Only when proponent is fully convinced about what is written in the EIA report, its implementation could be ensured. At present there is a practice of sending low quality EIA reports, thereby creating a problem in processing their approval. In a number of EIA reports, copying and pasting has created the problem. The result is mixed data-e.g., information related to a cement factory included in the EIA report of a hospital. The proponents might be unaware of these realities.

The MOEST has taken a varied time period for review and decision. For example, the former Ministry of 
Population and Environment took 295 days to approve the scoping document (SD) and Terms of Reference (TOR) of the Upper Tamakoshi Hydroelectricity Project, and the MOEST took 103 days to approve its final EIA report. The proponent took nearly three years and five months, between the approval of SD \& TOR and receipt of EIA report in MOEST, to prepare the EIA report of this project. In case of the Kawaswoti $132 \mathrm{kV}$ Sub-station Project, the SD and TOR was approved within 12 days and EIA report within 86 days. This gives an indication that approval process timeline depends upon the legal compliance and quality of the report submitted for approval.

There are several reasons that hindered timely approval of the EIA and its associated reports. However, decisions have been made within a very short time, to the extent possible. The causes of delayed decisions are related to a number of aspects. There are ample opportunities to minimise the cost of delay decisions, but they requires the joint efforts of the proponents and consultants, and the reviewing and approving institutions. Based on the review of EIA and associated reports, some of the reasons for delayed approval are summarised below:

1. In the case of the scoping document, the MOEST may receive the report with none, or incomplete, or unclear copy of the 15-days public notice. It may also not include the priority issues that should be considered during the preparation of the EIA report. In some cases, the MOEST has found the public notice published in the name of the consultant, not the proponent. In some of the water resource projects, approval has been delayed due to inconsistent information about the project implementation area, such as a list of VDCs or municipalities included in the survey licence and public notice for scoping.

2. Schedule 4 of the EPR of 1997 provides a format for the preparation of the TOR. In many cases, the TOR is not submitted following this Schedule. The MOEST sometimes also issues a revised TOR as per Rule 5 (3) of the EPR of 1997. But again, the report preparers have started copying the approved TOR. This is an ethical issue.

3. There are two bases for the preparation of the EIA report. One is the approved TOR and the other is by following Schedule 6 of the EPR of 1997. Three legal requirements should be complied with, before the approval of EIA report: (1) the proponent should submit the EIA report along with the proof of public hearing as per Rule 7 (2) of the EPR of 1997, (2) the proponent should submit the recommendation letter(s) of the concerned Village Development Committee(s) or Municipality(ies) along with the EIA report, and (3) the EIA report should be prepared consistent with the approved TOR.

In general, the MOEST has faced the following problems during the approval of the EIA report:

a. The public hearing is not done in the VDC or Municipality where the project will be implemented. This contradicts with Rule 7 (2) of the EPR of 1997.

b. The proof of public hearing is not attached in the EIA report; compliance with the legal provision is a pre-requisite for approval.

c. The proof of public hearing is attached but it may be technically questioned. For example, the proponent conducted public hearing at five districts in one of the project planned for implementation in 31 VDCs. A total of 53 participants attended the 'so-called' public hearing. Of them, 19 participants were either from the proponent's side or from district or VDCs where the project will not be implemented. Although the proponent complied with the legal provisions, it is very difficult to be convinced that a structured public hearing conducted in five separate districts was attended by only 33 local participants.

d. As per Rule 10 of the EPR of 1997, the MOEST has additional problems when considering the submitted recommenda-tion letters, in cases where the VDCs issue a letter mentioning 'approval (swikriti) for project implementation', or 'reaction (pratikriya) to the EIA report', or 'permission (anumati)' for project implementation or (sahamati) for project implementation. In general understanding, recommendation, approval, reaction or sahamati have different meanings.

e. There are also cases where the proponents have not addressed the comments and suggestions from the public hearings, the EIA Report Suggestion Committee or the MOEST itself, while revising/refining the reports. Weak responses and illogical or unclear or confusing write-ups have also delayed the approval process. Then the question arises: who should be 'blamed', and for what?

f. In some EIA reports, disjointed write-ups about baseline data and information, impacts, 
environment protection measures, and monitoring and auditing requirements have created additional problems for timely approval.

g. In some proposals, the Scoping Document, TOR and the EIA report have been submitted for approval after the construction stage of the project. Furthermore, proponents sometimes construct a project after the approval of Scoping Document and TOR but before the approval of EIA report. This is also an example of non-compliance of the environmental law.

4. Some of the impacts identified and predicted in the EIA reports are theoretical, unrealistic and nonsite specific. This is also validated from the field study. For example, an urban housing project submits scoping document with information on forest biodiversity.

The proponents must rectify these sorts of problems and submit their reports in compliance with the legal provisions. Their reports should be prepared based on the EIA principles and practices.

\section{Recent initiatives}

The MOEST is making every effort to improve the quality of EIA and associated reports. Lack of environmental monitoring reports, however, has made it difficult to know the level of compliance and effectiveness of the mitigation measures included in such reports. Lack of established mechanism for reporting about implementation of approved EIA reports has also limited the applicability of such reports, although the EPR has provisions for environmental monitoring and evaluation. Furthermore, lack of information about completion of the project construction stage has limited their effectiveness by neglecting to include information on programs and allocated budgets for environmental auditing, as per Rule 14 of the EPR of 1997.

Realising these constraints, the MOEST made several decisions in 2006 to facilitate timely approval of EIA and associated reports. Some of the recent initiatives are summarised below:

1. Once the EIA and associated reports are received at MOEST for approval, MOEST directly inform the proponent to submit additional information if required. Previously, the proponents were required to submit necessary information, including legal documents or revised report, through the concerned ministry. The new approach saves over three months of time.

2. All pending EIA reports are approved, including necessary conditions, if there are no legal complications.

3. In case the project affects resources such as forests, land and properties, compensatory measures have been adopted that, in general, are the last option in the EIA process. The basic purpose is impact avoidance, minimization and compensation.

4. The proponent is required to submit an annual report on environmental monitoring and evaluation to demonstrate level compliance and effectiveness of environment protection measures (benefit augmentation and adverse impacts mitigation measures), within the EIA report.

5. The proponent is also required to inform the MOEST within three months of completion of project construction in order to plan for conducting environmental auditing timely.

6. The MOEST is now approaching economic valuation of ecological goods and services of forest resources that will be directly affected by project activities. In the past, efforts were made to determine direct use values only. Once the new approach is in place, the proponent might also consider impacts of the project on indirect use of the natural resources that benefit local people and enhance the proponents' social responsibility.

7. Schedules 1 and 2 of the EPR have been amended and published in the Nepal Gazette of August 2007, taking into consideration inputs of the concerned institutions.

8. In order to assist the proponents in preparing quality EIA reports, the MOEST in November 2006, under its completed NORAD project, published framework guides to streamline the EIA approval process, environmental management plan, environmental monitoring, and environmental auditing. It has also published a handbook on licensing and EA process for hydropower projects.

\section{Conclusion}

Environmental assessment has multifold benefits in addressing impacts that will happen or are likely to happen with affected communities and natural resources. The EIA and associated reports are made public 
so that the stakeholders have the opportunity to raise their concerns, opinions and issues. If the EA reports are prepared based on correct principle and practice, they provide ample opportunities to make the development project environment-friendly and sustainable. For this, the proponents, consultants and reviewing and approving agencies should work closely together, to make projects more practical and implementable, and to benefit from the associated environmental impact assessment tools.

Batu Uprety is Chief, Environment Assessment Section, Ministry of Environment, Science and Technology, Government of Nepal. The views and opinions expressed in this article are personal and do not reflect the official opinion in any case.

Corresponding address: upretybk@wlink.com.np or upretybk@most.gov.np 